\title{
Northern Hemisphere drought risk in a warming climate
}

\author{
Daniel F. Balting $\mathbb{D}^{1 凶}$, Amir AghaKouchak $\mathbb{D}^{2,3}$, Gerrit Lohmann ${ }^{1,4}$ and Monica lonita $\mathbb{D}^{1,5}$
}

Drought frequency and severity are projected to increase in the future, but the changes are expected to be unevenly distributed across the globe. Based on multi-model simulations under three different future emissions and shared socioeconomic pathways, we show that a significant drought intensification is expected in dry regions, whereby the severity depends on greenhouse gas emissions and development pathways. The drought hotspots are located in the sub-tropical regions where a moderate to extreme summer drought in today's climate is expected to become a new normal by the end of the $21^{\text {st }}$ century under the warmest scenario. On average, under the warmest future scenario, the drought occurrence rate is projected to be $100 \%$ higher than that of the low emission scenario. Further, for the regions which are currently less affected by long-lasting droughts, such as the European continent, climate models indicate a significant increase in drought occurrence probability under the warmest future scenario.

npj Climate and Atmospheric Science (2021)4:61 ; https://doi.org/10.1038/s41612-021-00218-2

\section{INTRODUCTION}

In recent decades, historical climate observations have shown that many parts of the world are experiencing longer and more intense droughts as a consequence of observed atmospheric warming ${ }^{1}$. As a result, hydrological conditions are changing with potential regional climate change impacts on the society and ecosystems $\mathrm{s}^{2-4}$. Changing drought characteristics can lead not only to increased crop failures ${ }^{5}$, but also shifts in the entire ecosystem and vegetation zones ${ }^{6}$. Knowledge about the future drought occurrences, intensification and spatial distribution is therefore essential for developing adaptation policies and strategies.

In general, future drought projection is challenging since several relevant variables and complex processes contribute to the occurrence and severity of droughts. However, all droughtrelevant variables are not necessary represented well in the general circulation models (GCMs). In particular, future changes in potential evapotranspiration $\left(\mathrm{E}_{0}\right)$ and precipitation, which are integral parts of the hydrological cycle, are of major interest ${ }^{7,8}$. Different multimodel efforts have explored climate change impacts on regional drought variability, e.g. the studies based on Fifth Phase of the Coupled Model Intercomparison Project (CMIP5) ${ }^{9}$. Based on the CMIP5 simulations, hotspots of increased drought risk and severity have been identified ${ }^{10}$, and the mechanisms behind the changes of the key drought related variables, e.g., precipitation, $\mathrm{E}_{0}$ and large-scale atmospheric circulation, have been investigated ${ }^{11-15}$. Nevertheless, it is important to revise the previous assessment based on the recently released state-of-the-art model simulations participating in Phase Six of the Coupled Model Intercomparison Project $(\text { CMIP6 })^{16}$. The main motivation is that the physical descriptions of the climate system in CMIP6 simulations, spatial resolution, and the climate forcings have improved substantially ${ }^{16}$. To investigate droughts several indices are available in the literature ${ }^{17}$. In this study, the Standardized Precipitation Evapotranspiration Index $(\mathrm{SPEI})^{18,19}$, which represents a significant part of the atmospheric water balance, is used ${ }^{20}$. The advantage of the index is that it can be used for comparison across locations with different climatology because it is a standardized index for a given location relative to its long-term climatology ${ }^{21}$.

Using a multi-model ensemble mean drawn from CMIP6 database, we evaluate and investigate changes in the key driving factors of droughts, namely precipitation and $E_{0}$ in the historical runs and the radiative forcing scenarios developed for ScenarioMIP22. In this study, the conditions of low (Shared Socioeconomic Pathways 1-2.6; SSP1-2.6), medium (SSP2-4.5) and high (SSP5-8.5) emission scenario are investigated. Furthermore, we compute the occurrence rate of dry periods for the updated regions of Sixth Assessment report (AR6) of the Intergovernmental Panel on Climate Change (IPCC) ${ }^{23}$. The presented study focuses on the Northern Hemisphere during summer (June, July and August $(J J A)$ ), the season with the highest $E_{0}$ and the highest spatial distribution of droughts ${ }^{3}$. The overarching goal is to investigate the evolution of summer temperature and precipitation across different CMIP6 forcing scenarios, tendencies towards a wetter or drier climate and the occurrence of moderate to extreme droughts in three scenarios.

\section{RESULTS}

\section{Model evaluation}

In order to understand how drought is expected to change in the future using climate models, the quality of the simulations should be evaluated first. For this purpose, we perform a comparison between observed averages of summer temperature, precipitation and drought with modeled climate simulations for the period 1971 to 2000 (Fig. 1). Positive (negative) valuates indicate that the ensemble mean of the models has a greater (lower) value than that of the observations.

In Fig. 1a, Greenland and western Russia, parts of the Himalayas and Southeast Asia are significantly colder in the multi-model ensemble than in reality. In contrast, northern Canada, parts of central North America, northern India, the Arabian Peninsula and a band from the Mediterranean to central Asia are significantly warmer in the modelled climate state than in reality. Another pattern is shown in the precipitation difference (Fig. 1b) where

\footnotetext{
${ }^{1}$ Alfred-Wegener-Institute, Bremerhaven 27570, Germany. ${ }^{2}$ Department of Civil and Environmental Engineering, University of California, Irvine, CA, USA. ${ }^{3}$ Department of Earth System Science, University of California, Irvine, CA, USA. ${ }^{4}$ Physics Department, University of Bremen, Bremen 28359, Germany. ${ }^{5}$ Emil Racovita Institute of Speleology, Romanian Academy, Cluj-Napoca 400006, Romania. ${ }^{凶}$ email: Daniel.Balting@awi.de
} 

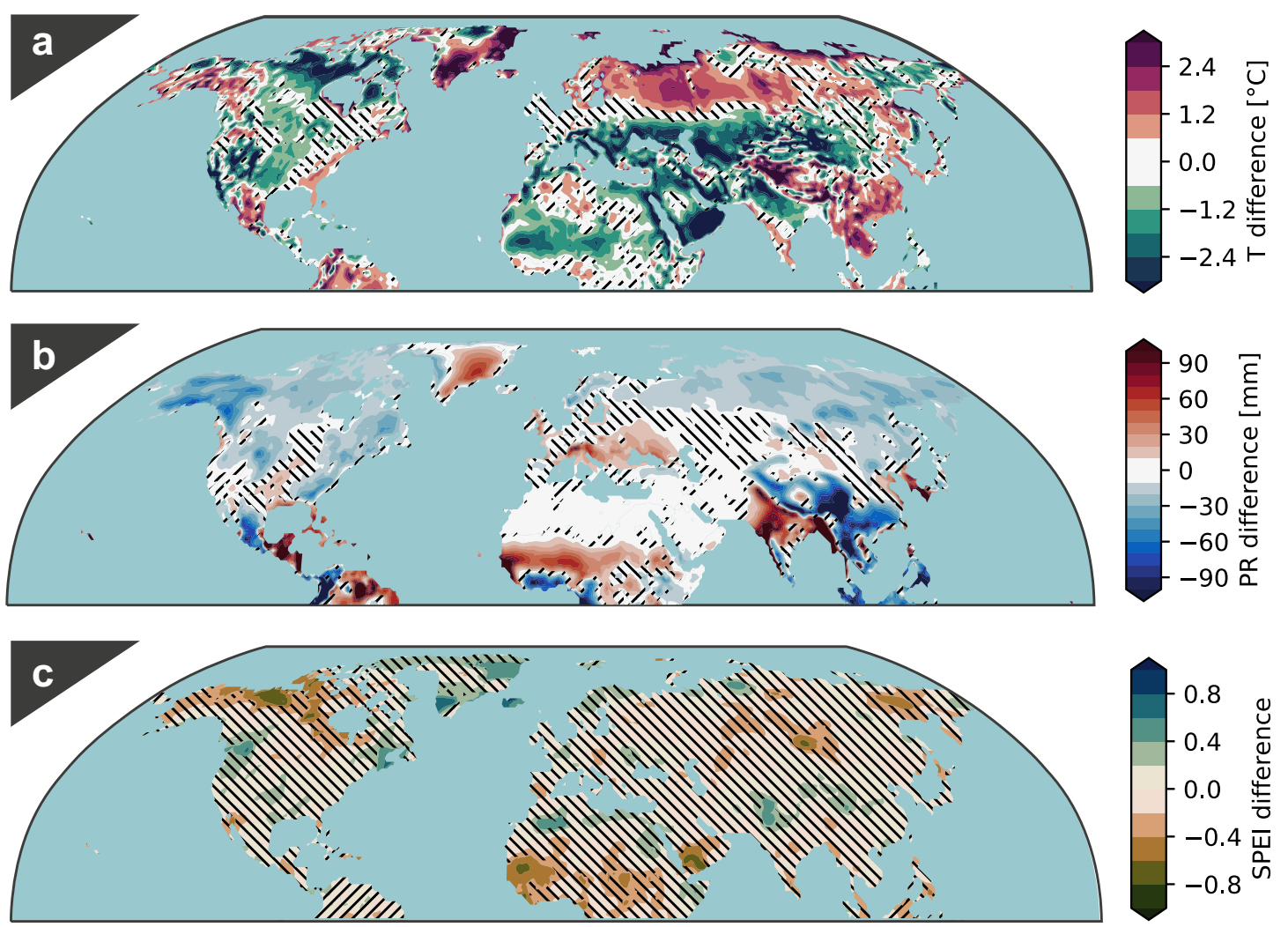

Fig. 1 Comparison of the modeled and observed climate for the period 1971-2000 (JJA only). a-c The climate simulations are averaged over the entire period and then subtracted from observations. a surface air temperature, $\mathbf{b}$ precipitation and $\mathbf{c}$ SPEI. The hatched areas indicate areas with insignificant changes according to the two-sided Student's $t$ test $(p<0.05)$.

large parts of North America, northern Central America, Southeast Asia and North Asia are characterized by significantly larger precipitation in the model ensemble mean. On the other hand, substantial underestimation of precipitation in the multi-model ensemble is observed in the northern Mediterranean region, southern Sahara and northern part of India compared to the observations. Nonetheless, the difference map of SPEI shows no significant overall difference between the model simulations and observations except in some small regions (Fig. 1c). Only small parts of northern North America, West Africa and the southern Arabian Peninsula and Greenland show a significant difference.

To investigate the consistency of the observed and climate model ensemble trends, we compare the differences of the temporal evolution of observed and modelled climate conditions for the periods 1975 to 1989 and 2000 to 2014 (Fig. 2). More specifically, we compare the relative change based on observations and historical model simulations during two historical periods (2000-2014 vs. 1975-1989). For all three variables, a negative value indicates a stronger trend between the two time periods in the observations than the climate model ensemble (a positive value represents the opposite). Comparison of temperature trends indicates that large parts of North America, Central Asia and Northwest Africa experience a higher temperature increase in observations than represented by the ensemble mean (Fig. 2a). In contrast, the ensemble mean shows a more pronounced warming trend in the eastern and northern Mediterranean region, northern Russia and northern Canada compared to observations. Considering precipitation (Fig. 2b), the trend in the Indian monsoon region is it is noticeably stronger than that of the ensemble mean of simulations. In addition, the difference in simulated and observed SPEI between these two periods shows that Central Europe, Central Africa and North
Greenland experience a much stronger trend in observations relative to the ensemble mean (Fig. 2c). On the other hand, Central North America and Northern Canada are characterized by a stronger trend in the ensemble mean compared to the observations (Fig. 2c).

\section{Projected summer temperature changes}

Future drought conditions, among others processes, depend on the temperature variability. Rising air temperature nonlinearly increases the saturated water vapor pressure at a rate of approximately $7 \% / \mathrm{K}$ according to the Clausius-Clapeyron relationship ${ }^{24}$. The increasing water holding capacity of air can lead to a higher amount of water that can theoretically evaporate (increase of $\mathrm{E}_{0}$ ). Changes in the greenhouse gas concentration combined with other local geographical and biophysical features can change the spatial and temporal variability of the temperature heterogeneously. The heterogeneity of the temperature pattern is shown in Fig. 3 for the Northern Hemisphere, where the temperature conditions for three different emissions are represented in terms of anomaly plots, i.e., the difference between the projected climate condition (2071-2100) and the historical (1971-2000) baseline.

An overall significant increase of the average summer temperature is shown in the Northern Hemisphere under all three future scenarios (Fig. 3), but with substantial variability in the magnitude and spatial variability among them (compare Fig. 3a, b and c). Under SSP1-2.6 (which represents a total anthropogenic forcing of $\left.2.6 \mathrm{~W} \mathrm{~m}^{-2}\right)^{22}$ the temperature increase is relatively homogenous over the whole Northern Hemisphere, with the magnitudes varying between 1 and $3^{\circ} \mathrm{C}$. A stronger warming is observed under SSP2-4.5 (which represents a total anthropogenic forcing of $\left.4.5 \mathrm{~W} \mathrm{~m}^{-2}\right)^{22}$ with summer temperature increases 

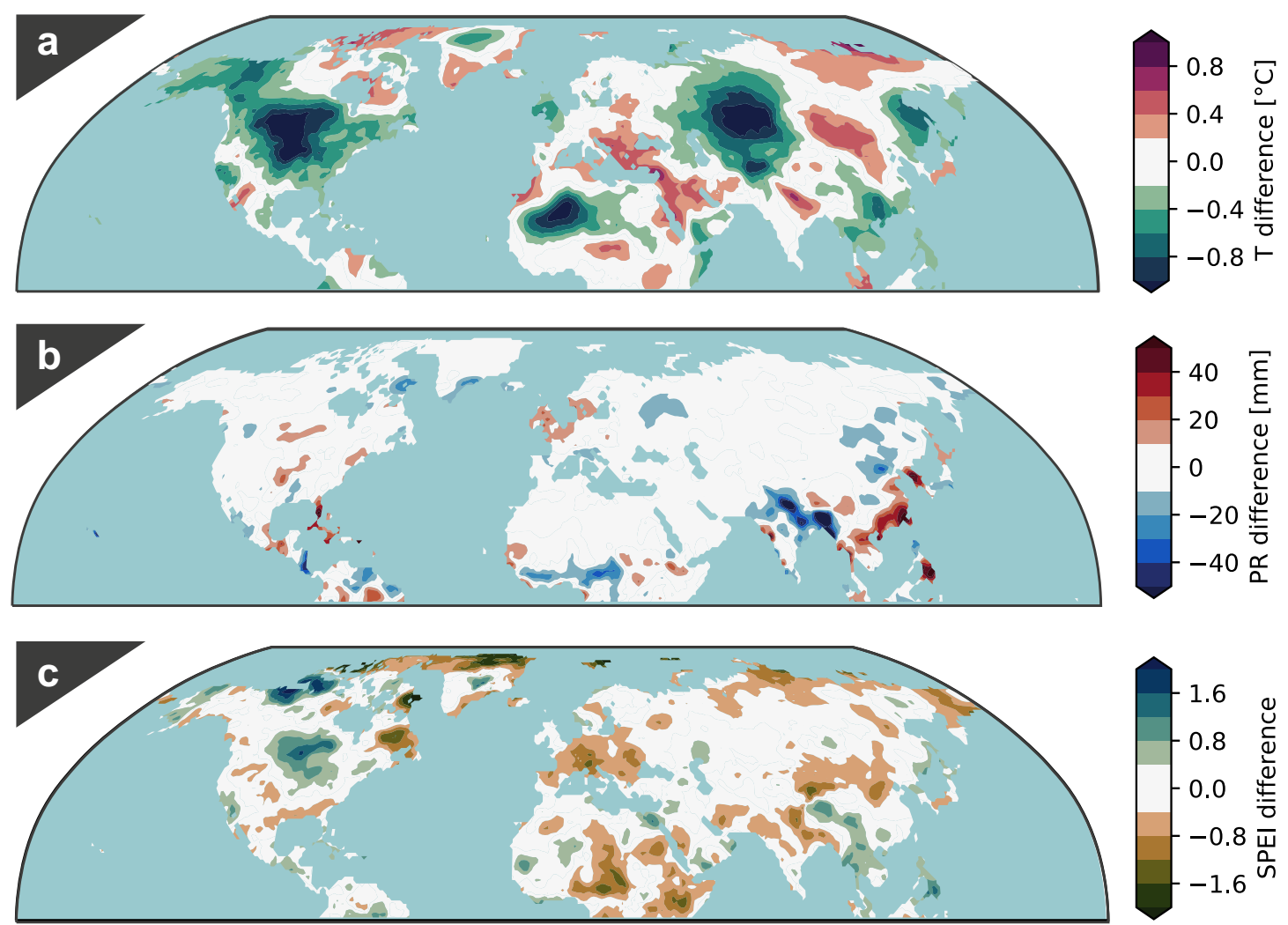

Fig. 2 Differences in trends in climate model simulations and observations. a-c The differences are shown for the periods $1975-1989$ and 2000 to 2014 (JJA only) in CMIP6 historical simulations relative to observations. A value of 0 represents that the trend in observations is the same as that of the model ensemble. Negative values indicate that trend in observations is stronger than in the model ensemble, whereas positive values show the opposite case. a Surface air temperature, $\mathbf{b}$ precipitation and $\mathbf{c}$ SPEI.

between $3^{\circ}$ to $5^{\circ} \mathrm{C}$ across the midlatitudes and the subtropics. The most affected areas, in terms of warming levels, are the Mediterranean region, Central North America, parts of Greenland and Siberia and Central Asia (Fig. 3b) located in the subtropics, midlatitudes and the high latitudes.

Similar warming hotspots are also observed under SSP5-8.5 scenario (Fig. 3c), which represents an anthropogenic forcing of $8.5 \mathrm{~W} \mathrm{~m}^{-2}$. The spatial variability of the temperature anomalies under SSP5-8.5 is higher compared to the other two scenarios (SSP-2.6 and SSP-4.5). In the Northern Hemisphere, the average summer temperature increases between $3^{\circ}$ to $8^{\circ} \mathrm{C}$, with the hotspots (the Mediterranean region, Central North America, parts of Greenland and Siberia and Central Asia) expected to experience between $7^{\circ}$ and $8^{\circ} \mathrm{C}$ of increase in temperature by the end of the century. Furthermore, it is noticeable that the tropics experience a weaker warming rate relative to the subtropics or mid-latitudes in all three scenarios. This is in agreement with the future warming distribution projections from other studies based on $\mathrm{CMIP5}^{25}$ and $\mathrm{CMIP6}^{26}$ (to evaluate consistency across CMIP6 simulations see Supplementary Fig. 1).

In addition to the average summer temperature, the same results are also presented for the maximum temperature (Tmax) and minimum temperature (Tmin) in Supplementary Figs. 2-5. The anomaly plots of both quantities share spatial characteristics similar to average temperature shown in Fig. 3. Nevertheless, the magnitudes of Tmax increases are more pronounced in the aforementioned hot spots relative to the Tmin.

\section{Projected precipitation and potential evapotranspiration}

The hydrological cycle is strongly dominated by the variability and amount of precipitation as the key driver of other variables such as runoff and soil moisture. Change in precipitation variability in the multi-model simulations and observations under the three scenario runs are shown in Fig. 4. The smallest absolute changes are found under SSP1-2.6 (Fig. 4a). Results show significantly more precipitation $(20-40 \mathrm{~mm})$ over a central band from East to West Africa and Southeast Asia. A smaller rate of precipitation increase is found in North Asia, Alaska and eastern coasts of North America. However, a significant precipitation deficit is shown in Central America and parts of the Mediterranean region. This is in agreement with previous studies based on $\mathrm{CMIP5}^{27}$ and $\mathrm{CMIP6}^{28}$ that indicate strengthening of the future Asian-northern African monsoon leading to wetter conditions, and weakening of the North American monsoon causing a drying pattern. According to recent findings ${ }^{28}$, the greenhouse gas forcing induces a stronger 'land-warmer-than-ocean' pattern, which enhances the Asian and West African monsoon low pressure system leading to increases in monsoon rainfall in these regions, and an El Niño-like warming, which reduces the North American monsoon rainfall.

The precipitation changes for the other two scenarios (Fig. $4 \mathrm{~b}$ and Fig. 4c) look very similar to SSP1-2.6 from a spatial point of view. However, the precipitation anomalies are larger and more spread out spatially relative to the presented hotspots in Fig. 4a. See for example the positive precipitation anomalies on the east and north coasts of Asia, North America and Europe in Fig. 4c relative to $4 a$. The precipitation increase on the east shores of Asia and North America is likely because of higher water holding capacity of the atmosphere and warm water transport from ocean circulation. Fig. 4c indicates that Central America, Europe (except Northern Europe), North Africa, Central Asia will likely experience a significant negative precipitation anomaly compared to the historical observations. To evaluate consistency of 

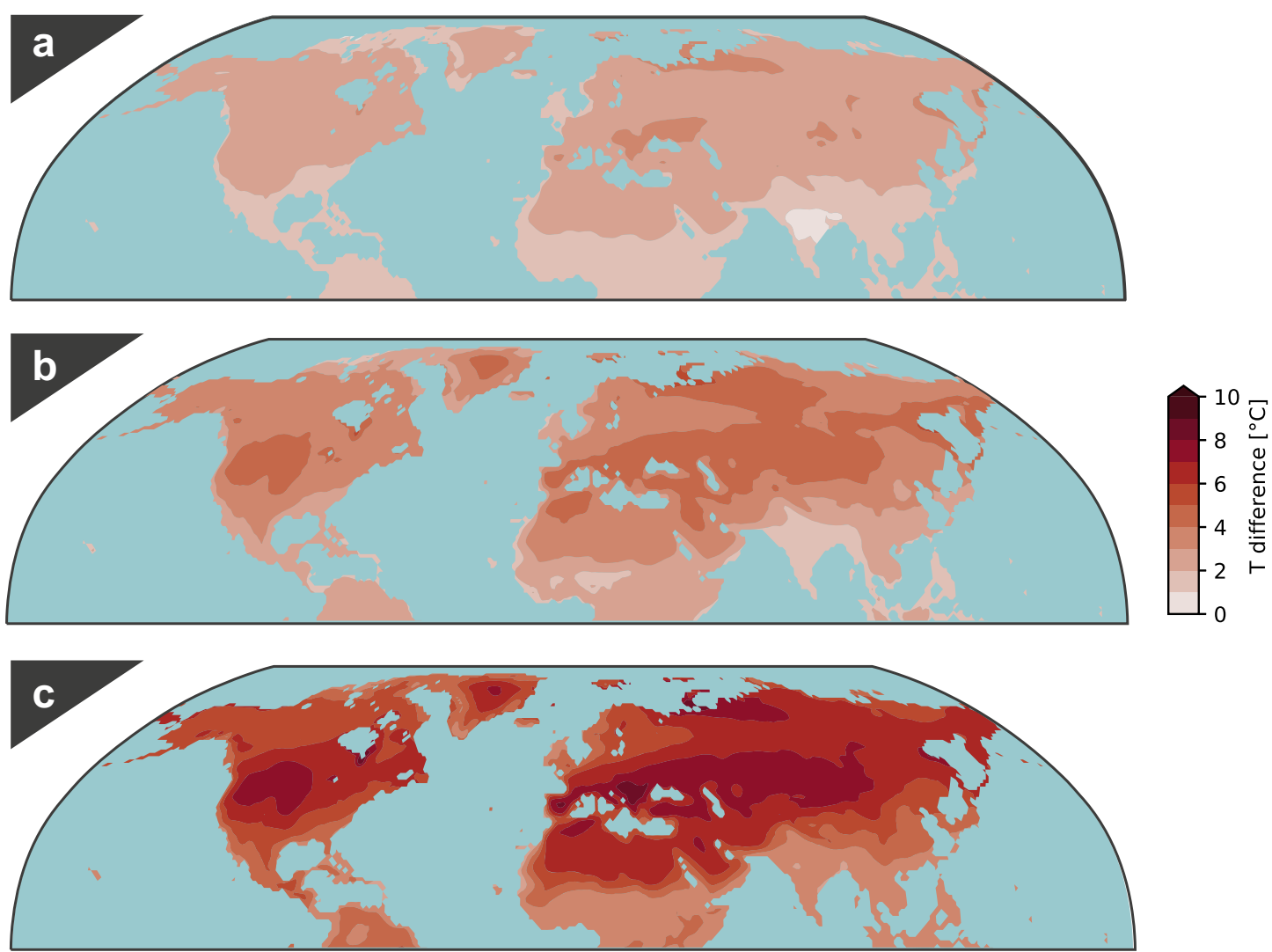

Fig. 3 Projected changes to the Northern Hemisphere summer temperature. a-c Spatial distribution of the summer temperature anomalies in the Northern Hemisphere based on the multi-model projected changes (2071-2100) based on SSP1-2.6 (a), SSP2-4.5 (b) and SSP5-8.5 (c) scenarios relative to the historical summer temperature during the 1971-2000 baseline period. All changes are significant according to the two-sided Student's t test $(p<0.05)$.

the multi-model CMIP6 ensemble members the interested reader is referred to Supplementary Fig. 6.

The $\mathrm{E}_{0}$ is another essential component of the climatic and land surface water balance, because it represents the atmospheric demand for moisture. Recent studies indicate that the projected $\mathrm{E}_{0}$ in the CMIP6 multi-model simulations is higher than in CMIP5 under a comparable emission scenario, possibly because CMIP6 models simulate stronger warming for a given forcing or scenario $^{29}$. Due to the relation between $E_{0}$ and temperature, the anomaly figures of $E_{0}$ for the different SSPs show similar characteristics as the projected temperature changes in Fig. 3. The strongest significant increase of $E_{0}$ is found for the subtropics and the midlatitude under SSP1-2.6 (Fig. 5a). The hotspots for the strongest increase of the $E_{0}$ are Central North America, the Mediterranean region, Central Asia, the Arabian Peninsula and North Africa. However, no significant change of $E_{0}$ is shown for parts of India and northern Nigeria. Similar insignificant changes in the same locations are also observed under SSP2-4.5, while significant increase of $E_{0}$ in the hotspots is more pronounced in this scenario (Fig. 5b). Under SSP5-8.5 (Fig. $5 \mathrm{c}$ ), the highest positive anomalies are shown over Spain, around the Black Sea and parts of North Africa. A belt of strong $E_{0}$ increase is shown from Spain and North Africa towards Central Asia. Also, an increase in $E_{0}$ is shown over the central and southern parts of North America. It is noticeable that the increase in $E_{0}$ is lower in the tropics compared to the subtropics and midlatitudes in all three scenarios. Evaluating consistency of the multi-model CMIP6 ensemble members indicates similar results with the exception of the African tropics, India and parts of Greenland (Supplementary Fig. 7).

\section{Drought conditions by the end of $21^{\text {st }}$ century}

Projected changes in drought characteristics are closely associated with the presented changes to temperature, precipitation and $E_{0}$ (Fig. 6). Under SSP1-2.6 (Fig. 6a), significant drier conditions are projected over North Africa, Saudi Arabia, Central America, the Mediterranean region, Central America and the southwest of the USA, which are indicated by the negative SPEI values. The projected drying trend under SSP1-2.6 is primarily driven by the expected temperature increase (Fig. 3a) leading to a higher $E_{0}$ (Fig. $5 a$ ). The higher $E_{0}$ cannot be compensated by an increase in precipitation (Fig. 4 a, see also Supplementary Figs. 8-9) leading to overall drier conditions in the summer. In contrast, significant wetter conditions are detected for parts of the coastal regions of Asia, parts of the east coast of North America, eastern parts of Greenland and Alaska. In these regions, the increase in precipitation is more pronounced relative to increase in $E_{0}$, resulting in overall wetter conditions (Figs. 4a, 5a, 6a, Supplementary Figs. 8-9).

SSP2-4.5 (Fig. 6b) exhibits similar hotspots to those of SSP1-2.6 (e.g., significant negative SPEI anomalies over North Africa, Central Asia and Saudi Arabia). However, regions with a negative SPEI anomaly are more spreadout and drier mainly driven by projected reduction in precipitation (Fig. 4b, Supplementary Figs. 8-9) as well increase in $E_{0}$ (Fig. 5b). Over North America, significant drier conditions are found in Western North America and Central America. The drier conditions in Central America are also driven by a significant increase in $E_{0}$ (Fig. $5 \mathrm{~b}$ ) and a precipitation deficit (Fig. 4b, Supplementary Figs. 8-9). On the other hand, East Asia, Greenland and Alaska are characterized by a tendency towards wetter conditions. 

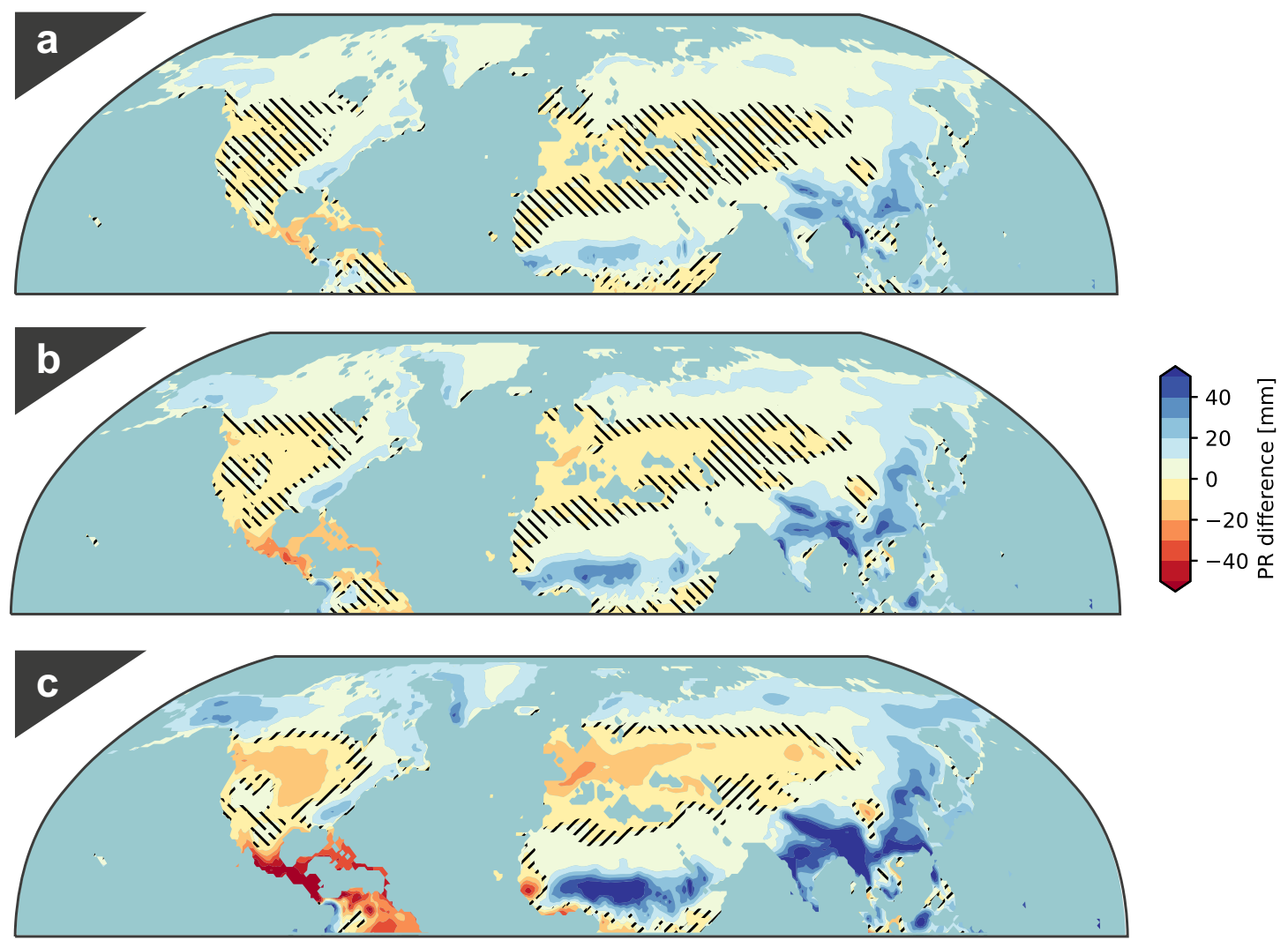

Fig. 4 Changes to summer precipitation under SSP1-2.6, SSP2-4.5 and SSP5-8.5. a-c Averaged anomalies of summer precipitation under SSP1-2.6 (a), SSP2-4.5 (b) and SSP5-8.5 (c) in the Northern Hemisphere. A reference period of 1971-2000 relative to the period 2071-2100 is used for deriving anomalies. The hatched areas indicate areas with insignificant changes according to the two-sided Student's $t$ test $(p<0.05)$.

An even stronger drying trend is visible under SSP5-8.5 (Fig. 6c) with hotspots expanding over the Mediterranean region, Saudi Arabia, North Africa, Central Asia, Central Europe, Central America, Central North America, West North America and the Middle East. The drier conditions in these regions are driven by increases in $\mathrm{E}_{0}$ (Fig. 5c) compared to SSP1-2.6 (Fig. 5a) and SSP2-4.5 (Fig. 5b) as well as decreases in precipitation (Fig. 4c, Supplementary Figs. 8-9). Comparing different scenarios, an expansion of dry conditions is noted from the subtropics towards the midlatitudes by the end of the $21^{\text {st }}$ century. This is also shown for drought conditions in spring (Supplementary Figs. 11-13). The drought hotspots identified in this study are broadly consistent with regional and global studies based on CMIP5 $5^{3,8,10,30-32}$ and CMIP6 ${ }^{33}$ simulations. However, parts of Greenland, East Asia, North East Asia, Alaska and Scandinavia show a positive SPEl anomaly indicating wetter conditions in the future (Fig. $6 \mathrm{c}$ ). The reason for that is the precipitation increases in these regions and the corresponding small increase in $\mathrm{E}_{0}$ (Figs. $4 \mathrm{C}$ and $5 \mathrm{c}$ ). The majority individual members in the multi-model CMIP6 simulations confirm the presented results based on the ensemble mean (see Supplementary Fig. 15).

\section{Occurrence of dry periods and extreme droughts at the end of $21^{\text {st }}$ century}

Based on the results presented in the previous section, we have shown that the projected warming has an influence on the global distribution of dry regions and the severity of dryness based on the ensemble mean of CMIP6 simulations. However, anomaly plots of a 30 years period do not offer any insights on temporal variability of dry conditions. Therefore, the occurrence rate (see Methods for the definition) of SPEI $<-1.5$ for the updated AR6 regions ${ }^{23}$ are computed to investigate the risk of moderate to extreme droughts under the same three future scenarios. Since the SPEI is a standardized index based on a reference period (here, 1971 to 2000), each standardized value corresponds to an occurrence probability. The selected SPEI < -1.5 refers to $6.7 \%$ occurrence probability (approximately one drought event in 15 years).

In Fig. 7, the occurrence rate is shown for selected regions in Europe and Asia (for more regions see Supplementary Figs. 15-20). The occurrence rate $\lambda$ is the probability of SPEI falling below -1.5 during one year. If $\lambda(a)^{-1}=1$, it means that a SPEI value below -1.5 can be observed every year whereas $\lambda(a)^{-1}=0.5$ would mean that this SPEl threshold is reached every two years. For the Mediterranean region (MED), it is shown that the risk of a SPEI below -1.5 is projected to change over time and is highly dependent on the choice of scenario (Fig. 7a). Under SSP1-2.6, a significant positive trend is shown until 2030 whereas a small negative trend can be found thereafter. From 2038 onwards, the occurrence rate decreases. It is noted that the median stabilizes at $\lambda(a)^{-1}=0.45$ from 2064 onwards

Under SSP2-4.5 and SSP5-8.5, an entirely different pattern is projected. Under SSP5-8.5, the ensemble median is characterized by a significantly increasing $(p<0.01)$ occurrence rate reaching the maximum of $\lambda(a)^{-1}=1$ in 2081 . The $75^{\text {th }}$ percentile is characterized by a steep trend towards a $\lambda_{75}(a)^{-1}=1$ and remains at this high level from 2029 onwards. This indicates that a drought event which is characterized by a SPEI $<-1.5$ in today's climate is projected to occur every year by the end of the $21^{\text {st }}$ century. The strong increase in the drought risk is driven by the projected increase to $E_{0}$ and decrease to precipitation (Figs. 4c and $5 c$ ), associated with a projected widening of the Hadley Circulation that shifts downwelling and inhibits precipitation ${ }^{34}$. The occurrence rates under SSP2-4.5 also show significant increases 

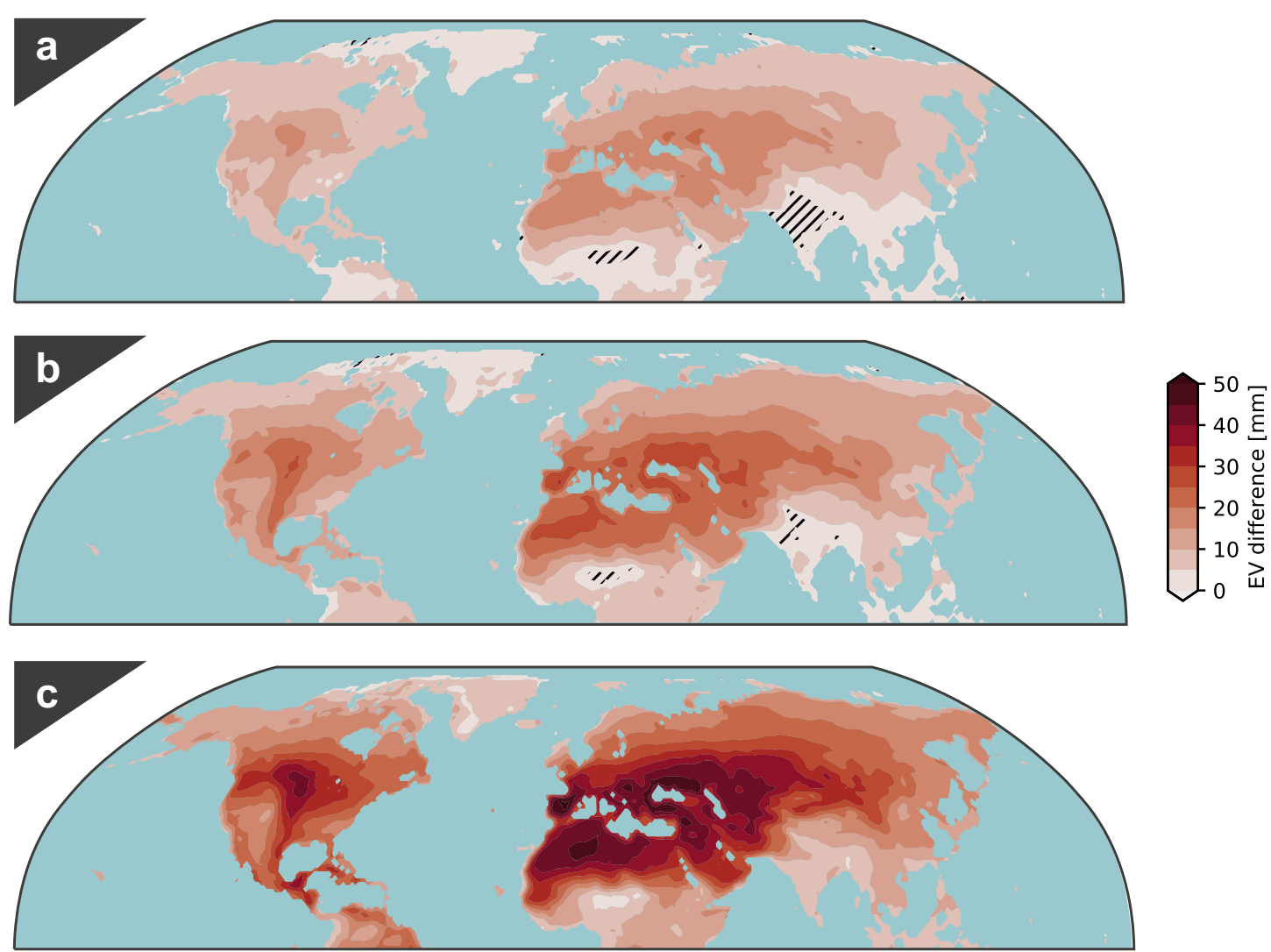

Fig. 5 Changes to summer potential evapotranspiration under SSP1-2.6, SSP2-4.5 and SSP5-8.5. a-c Averaged anomalies of summer potential evapotranspiration under SSP1-2.6 (a) and SSP2-4.5 (b) and SSP5-8.5 (c) in the Northern Hemisphere for the period 2071-2100 relative to the baseline period of 1971-2000. The hatched areas in all three subfigures indicate areas with insignificant changes according to the two-sided Student's t test $(p<0.05)$.

$(p<0.01)$, reaching a median occurrence rate of $\lambda(a)^{-1}=0.91$ by the end of the $21 \mathrm{st}$ century. The $75^{\text {th }}$ percentile, however, reaches the upper bound of $\lambda_{75}(a)^{-1}=1$. This shows that despite the lower warming compared to SSP5-8.5, the drought risk under SSP2-4.5 is projected to enhance by the end of the 21 st century. The weaker occurrence rate in SSP2-4.5, in comparison to SSP5-8.5, is related to the lower total and input rate of greenhouse gas emissions in SSP2-4.5 22 . Results show that the MED region will be one of the hotspots for dryer conditions by the end of the $21^{\text {st }}$ century. In contrast to SSP1-2.6, no decrease of the occurrence rate is shown for the MED region under SSP2-4.5 and SSP5-8.5.

The northern bordering region of Central Europe (CEU) is characterized by totally different occurrence rates for the three different SSPs. Under SSP1-2.6, the occurrence rate of the median, $75^{\text {th }}$ percentile and $25^{\text {th }}$ percentile do not exhibit significantly increasing trends $(p>0.01)$. While the median of the occurrence rate under SSP2-4.5 does not show a significantly increasing $(p>$ 0.01 ), the $75^{\text {th }}$ percentile does and reaches $\lambda_{75}(\mathrm{a})^{-1}=0.52$ by the end of the $21^{\text {st }}$ century. In contrast to the occurrence rates under SSP1-2.6 and SSP2-4.5, the occurrence rate under SSP5-8.5 exhibits a significantly increasing trend $(p<0.01)$. From around 2050 the median increases and reached $\lambda(a)^{-1}=0.55$. Based on the results, it can be concluded that the drought risk in Central Europe is main projected to increase significantly under the SSP5-8.5 scenario.

In East Europe (EEU) and West Siberia (WS), one can see a similar behavior as in the CEU. For both regions, no significant increasing trend $(p>0.01)$ of the occurrence rate can be found under SSP12.6 and SSP2-4.5, whereas a significant increasing trend $(p<0.01)$ appears under SSP5-8.5 which starts around 2050. The median, $25^{\text {th }}$ and $75^{\text {th }}$ percentiles in EEU and WS by the end of $21^{\text {st }}$ century can be summarized as follows: EEU $\lambda(a)^{-1}=0.41\left(\lambda_{25}(a)^{-1}=0.31\right.$, $\left.\lambda_{75}(a)^{-1}=0.78\right)$; WS $\lambda(a)^{-1}=0.46\left(\lambda_{25}(a)^{-1}=0.22, \lambda_{75}(a)^{-1}=0.79\right)$.

The occurrence rate of SPEI below -1.5 during one year is also investigated over the North America (Fig. 8). The West North America (WNA) region is characterized by a clear separation of the different occurrence rates under the three analyzed SSPs. From 2050 , a significant increase $(p<0.01)$ of the drought occurrence rate is shown under SSP5-8.5. The occurrence is significantly increasing with the median and lower and upper bounds reaching $\lambda(a)^{-1}=0.78\left(\lambda_{25}(a)^{-1}=0.49, \lambda_{75}(a)^{-1}=1\right)$, respectively. In contrast, no significant trend in the occurrence rate is shown under SSP1-2.6 and SSP2-4.5, where the occurrence rates by the end of the $21^{\text {st }}$ century are $\lambda(a)^{-1}=0.22\left(\lambda_{25}(a)^{-1}=0.03, \lambda_{75}(a)^{-1}=0.32\right)$ and $\lambda(a)^{-1}=0.36\left(\lambda_{25}(a)^{-1}=0.25, \lambda_{75}(a)^{-1}=0.46\right)$, respectively.

Similar to CEU, WS and EEU, Central North America (CNA) does not show a significant trend in the occurrence rate of dry conditions under SSP1-2.6 and SSP2-4.5. Another similarity is that the occurrence rate under SSP5-8.5 shows a significant increasing trend $(p<0.01)$. The positive trend starts around 2050 with the occurrence rates reaching $\lambda(a)^{-1}=0.45\left(\lambda_{25}(a)^{-1}=0.35, \lambda_{75}(a)^{-1}\right.$ $=0.85$ ) by the end of the $21^{\text {st }}$ century.

The region of North Central America (NCA) shows a similar occurrence rate that of the MED region. The strongest and significant increase $(p<0.01)$ of the occurrence rate is observed under SSP5-8.5 with $\lambda(a)^{-1}=0.98\left(\lambda_{25}(a)^{-1}=0.85, \lambda_{75}(a)^{-1}=1\right)$. Fig. $8 \mathrm{c}$ displays that $75^{\text {th }}$ percentile reaches an occurrence of $\lambda_{75}(a)^{-1}=1$ around 2082 and remains thereafter. A not as pronounced yet significant increasing trend $(p<0.01)$ is projected under SSP2-4.5 with $\lambda(\mathrm{a})^{-1}=0.79\left(\lambda_{25}(\mathrm{a})^{-1}=0.59, \lambda_{75}(\mathrm{a})^{-1}=0.87\right)$ by 2100 . Despite the weaker warming in SSP2-4.5, the risk of drought is still projected to increase without levelling off. 

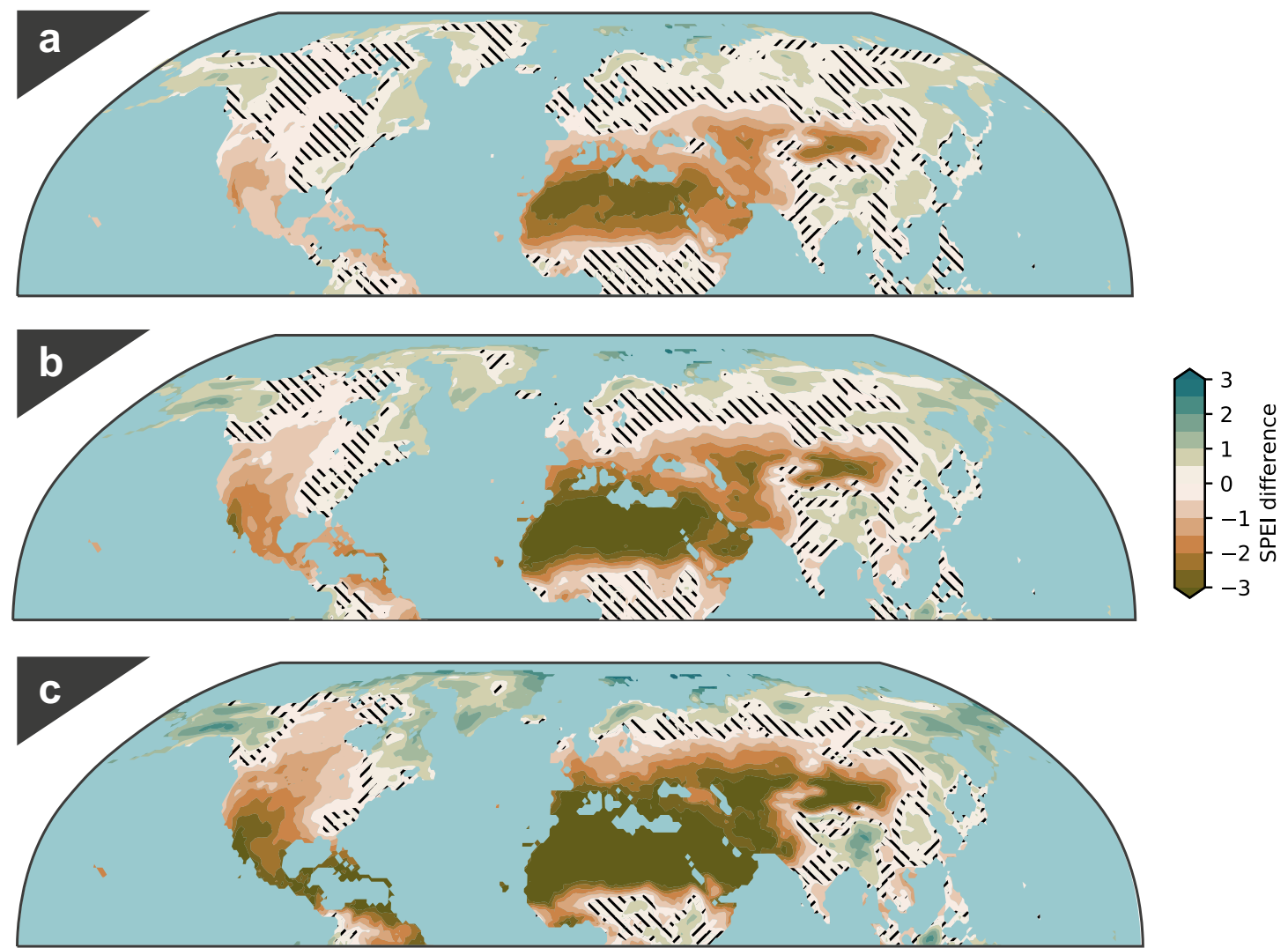

Fig. 6 Changes to summer drought conditions under SSP1-2.6, SSP2-4.5 and SSP5-8.5. a-c Averaged anomalies of summer droughts under SSP1-2.6 (a) and SSP2-4.5 (b) and SSP5-8.5 (c) in the Northern Hemisphere for the period 2071-2100 relative to the baseline period of 1971-2000. The hatched areas in all three subfigures indicate areas with insignificant changes according to the two-sided Student's $t$ test $(p<0.05)$.

Furthermore, the occurrence rate under SSP1-2.6 is projected to increase until 2050 and decrease then after with $\lambda(a)^{-1}=0.23$ $\left(\lambda_{25}(a)^{-1}=0.07, \lambda_{75}(a)^{-1}=0.32\right)$ by the end of the $21^{\text {st }}$ century without showing a statistically significant trend $(p<0.01)$.

\section{DISCUSSION}

In this study, we have quantified changes in the drought occurrence based on the newly published CMIP6 simulations ${ }^{16}$. Our results based on the anomaly and frequency analysis indicate an increase in the occurrence of summer droughts and an intensification of droughts in the majority of the subtropics and parts of the midlatitudes, mainly due to an increase of greenhouse gases $^{20}$. In addition, hotspots for drought occurrence, such as the Mediterranean region, can experience more widespread events depending on the magnitude of greenhouse gas emissions and Shared Socioeconomic Pathways. Some of the hotspots identified in our study have also been identified in studies based on the CMIP5 $5^{3,8,10,30-32,35}$ and CMIP6 ${ }^{33}$ which gives additional confidence to our results. For this reason, we confirm previous findings that the projected droughts ${ }^{33}$ and drought risk in CMIP5 and CMIP6 are broadly consistent.

One reason for intensification of droughts in the Northern Hemisphere subtropics is that the summer temperature is projected to rise leading an increase in $E_{0}$ and sometimes a decrease in precipitation ${ }^{10,30-32}$. The increase in $E_{0}$ is suggested to double the percentage of the global land area projected to experience significant drying based on CMIP5 simulations by the end of 21 st century ${ }^{33}$ and is a key variable to understand drought variability ${ }^{7}$. Recent studies indicate that the projected $E_{0}$ is more pronounced in CMIP6 multi-model simulations than in CMIP5 ${ }^{29}$, mainly because of the changes in the total anthropogenic forcing ${ }^{22}$. As a result, more intense droughts are projected based on CMIP6 simulations in comparison to studies based on CMIP $5^{11}$.

Previous studies addressing changes in hydrological conditions based on CMIP6 ${ }^{33}$ have projected declines in soil moisture and runoff as a consequence of continued greenhouse gas emissions. Although the SPEl index does not include soil parameters in the calculation, many of the predicted trends in soil moisture across the soil column match the drought hotspots presented in our results (Fig. 9a-c, Supplementary Fig. 10). For example, soil moisture projections indicate robust and significant decreases in soil moisture in large parts of the Mediterranean, Central America, North Central America and North South America (Fig. 9, Supplementary Fig. 10). This is consistent with the projected of precipitation and temperature (Figs. 3-4). Nevertheless, there are differences too. For example, the SPEI indicates that large parts of Central Asia, parts of Northwest India and the Middle East are at greater risk of drought depending on the strength of emissions (Fig. 6), whereas soil moisture is projected to increase in the same regions (Fig. 9) that require future investigation.

The projected increase in occurrence rate of droughts over the selected AR6 regions indicates a significant stress on economy ${ }^{36}$, agriculture $^{37}$, migration ${ }^{38}$, and ecosystems ${ }^{39}$ of the regions in the future. Northward shifts in forests and vegetation ${ }^{6}$ leading to shifts in the habitat distributions ${ }^{40}$ is among major ecosystem impacts. Changes to habitats can also contribute to significant alteration of the carbon cycle ${ }^{41}$. Furthermore, the projected climate conditions are likely to increase vegetation mortality due to droughts and other relevant drivers such as fires and infestation ${ }^{42}$. 

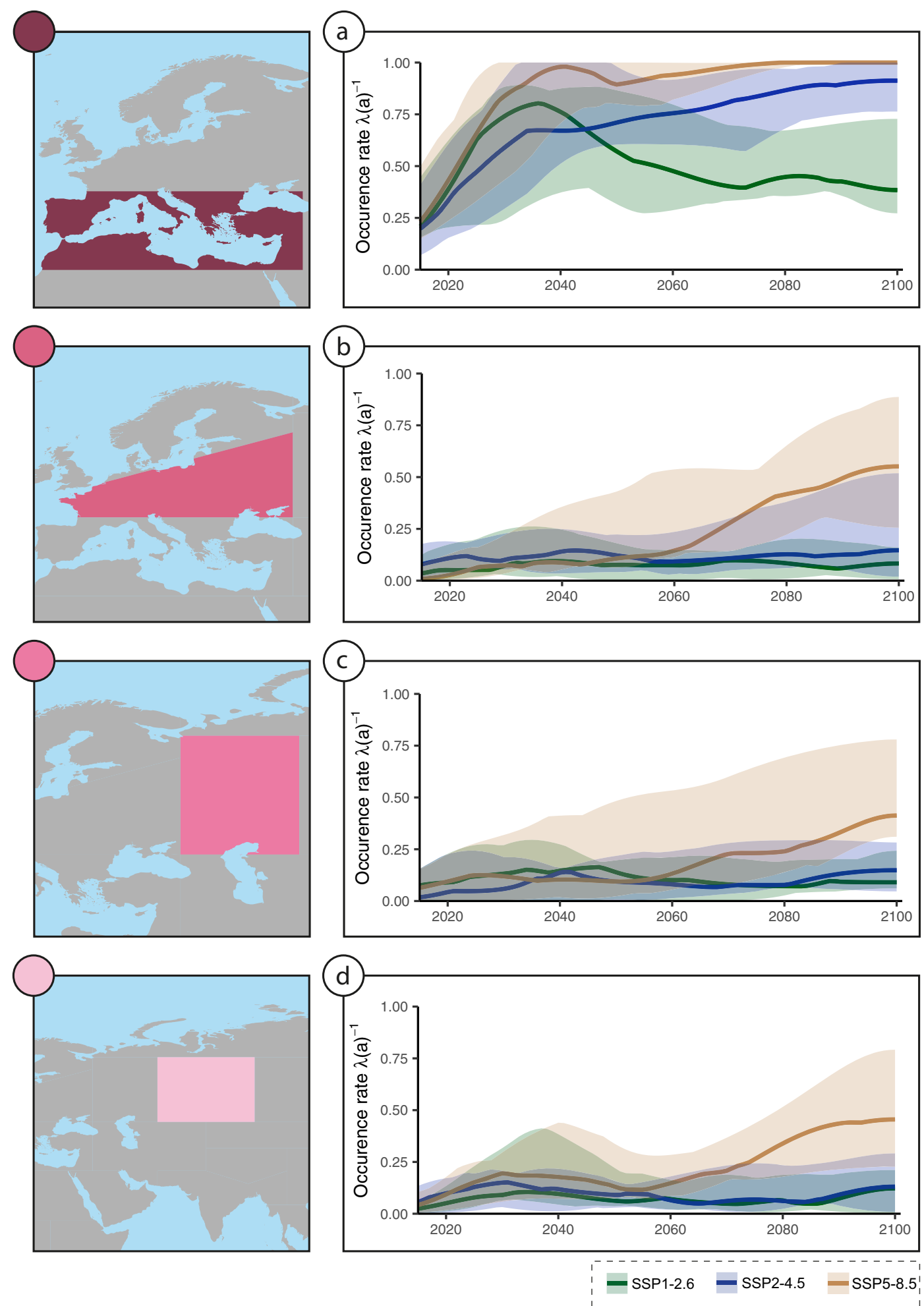

Fig. 7 Projected drought conditions for selected AR6 regions ${ }^{23}$ in Europe and Asia. a-d Temporal evolution of occurrence rate of SPEI below -1.5 under different future climate scenarios (SSP1-2.6, SSP2-4.5, SSP5-8.5). $\lambda(a)^{-1}=1$ indicates a SPEI value below -1.5 can be observed every year. The SPEI is derived based on the baseline period of 1971 to 2100 . The medians of the model ensemble from CMIP6 are highlighted. The $25^{\text {th }}$ and $75^{\text {th }}$ percentiles of the model ensemble for each scenario are indicated with shaded color around the median.

We acknowledge that the model simulations and SSPs are uncertain and characterized by different limitations that have been evaluated in different studies ${ }^{43}$. Some challenges include limitations associated with physical representation of clouds and uncertainty in precipitation projections in $\mathrm{GCMs}^{44}$. Furthermore, current land surface models do not simulate all the hydrological subsurface processes well contributing to uncertain projections ${ }^{3}$. Also, dynamical phenomena like atmospheric blocking, which are relevant for climate extremes, are generally poorly represented by climate models or are subject to biases ${ }^{45}$. In addition, PET 

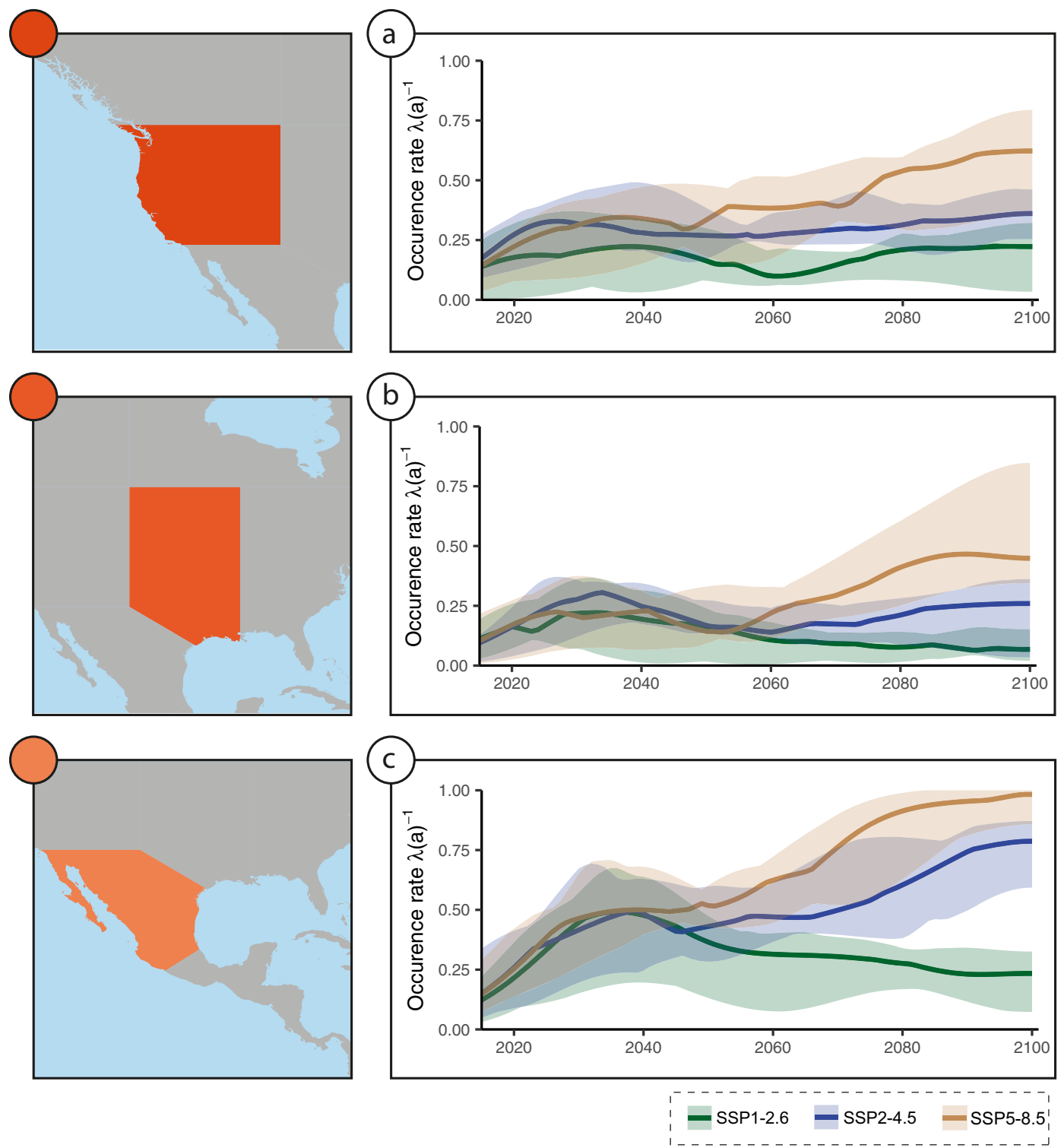

Fig. 8 Projected drought conditions for selected AR6 regions ${ }^{23}$ in North America. a-d Temporal evolution of occurrence rate of SPEI below -1.5 under different future climate scenarios (SSP1-2.6, SSP2-4.5, SSP5-8.5). $\lambda(\mathrm{a})^{-1}=1$ indicates a SPEI value below $-1.5 \mathrm{can}$ be observed every year. The SPEI is derived based on the baseline period of 1971 to 2100 . The medians of the model ensemble from CMIP6 are highlighted. The $25^{\text {th }}$ and $75^{\text {th }}$ percentiles of the model ensemble for each scenario are indicated with shaded color around the median.

estimation is also subject to high uncertainty which leads to biases in drought projections. Other challenges include uncertain and complex role of vegetation processes ${ }^{14,46}$ in a warming climate, different climate sensitivity of $\mathrm{GCMs}^{47}$ or uncertainties in future radiative forcing ${ }^{3}$ all of which contribute to uncertainties in drought projection.

Despite the uncertainties of the GCMs, they can reasonably simulate the general tendencies of regional drought trends and patters in the future. As shown in this paper, our historical evaluation exhibits reasonable consistency between spatial patterns in climate model simulations and observations (Fig. 1). However, there are differences in how well the models represent trends in drought conditions - e.g., multi-model ensemble underestimating the drying trend in Central Europe (Fig. 2). We note that the presented results are consistent with drought hotspots identified in prior studies. Our findings indicate that projected droughts are sensitive to the greenhouse gas emissions and Shared Socioeconomic Pathways. The warmer the future climate, the more intense are the projected droughts spreading from the subtropics to the mid-latitudes. In a relative sense, droughts under SSP1-2.6 are less intense compared to more unfavorable scenarios which highlights the need to reduce greenhouse emissions to reduce future drought impacts.

\section{METHODS}

\section{Data}

In this study, we analyze four climate variables from the CMIP6 ${ }^{16}$ simulations from historical simulations (1850 to 2014) and future projections (2015 to 2100) based on different shared socioeconomic pathways (SSPs) ${ }^{22}$. To present the analysis for a wide range of scenarios, we used divers SSPs including SSP1-2.6, SSP2-4.5 and SSP5-8.5. The criteria for selecting climate models include: ${ }^{47}$ models must (i) provide the relevant variables, (ii) include simulations for the period 1850 to 2100 , and (iii) not have duplicate time steps or missing time steps.

The maximum surface temperature (Tmax), minimum surface temperature (Tmin), mean surface temperature $(T)$, soil moisture, precipitation, 

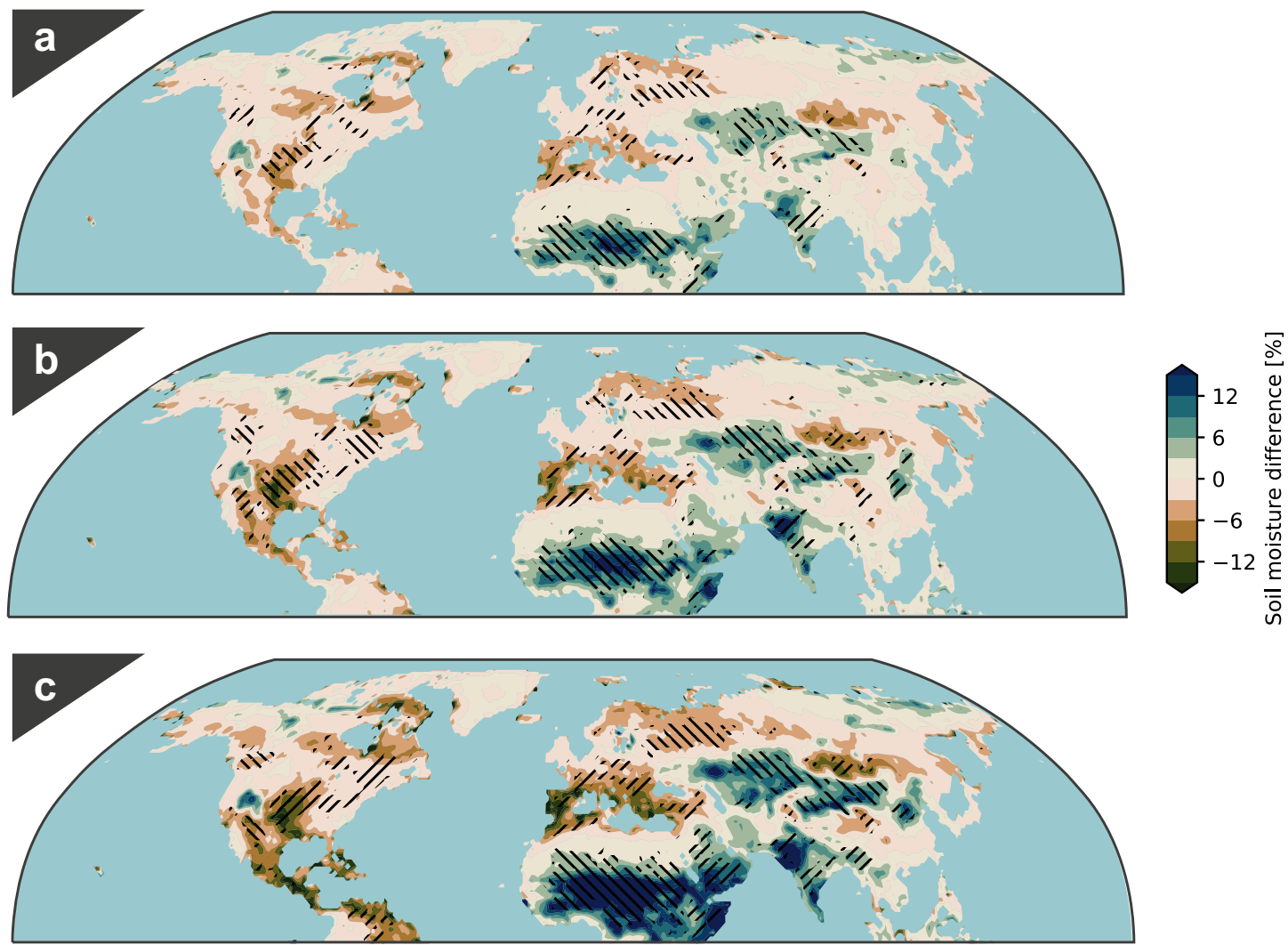

Fig. 9 Averaged anomalies of summer soil moisture (entire column) under SSP1-2.6, SSP2-4.5, and SSP5-8.5. a-c Averaged anomalies of summer soil moisture under SSP1-2.6 (a) and SSP2-4.5 (b) and SSP5-8.5 (c) in the Northern Hemisphere for the period 2071-2100 relative to the baseline period of 1971-2000. The hatched areas indicate areas where 10 of the 11 CMIP6 models show the same sign of change (data from the AWI-CM-1-1-MR model are not used in this figure because the required variable does not exist).

Table 1. Description of the used climate model ensemble for the historical run and three future scenarios.

Number of used Historical SSP1-2.6 SSP2-4.5 SSP5-8.5 References realizations

\begin{tabular}{llllll}
\hline ACCESS-CM2 & 2 & 1 & 1 & 1 & 57 \\
ACCESS-ESM1-5 & 3 & 3 & 3 & 3 & 58 \\
AWI-CM-1-1-MR & 2 & 1 & 1 & 1 & 59 \\
EC-Earth3 & 3 & 1 & 1 & 1 & 60 \\
EC-Earth3-Veg & 2 & 3 & 3 & 3 & 61 \\
INM-CM4-8 & 1 & 1 & 1 & 1 & 62 \\
INM-CM5-0 & 10 & 1 & 1 & 1 & 63 \\
IPSL-CM6A-LR & 32 & 6 & 6 & 6 & 64 \\
MIROC6 & 10 & 3 & 3 & 3 & 65 \\
MPI-ESM1-2-HR & 7 & 2 & 2 & 2 & 66 \\
MPI-ESM1-2-LR & 10 & 10 & 10 & 10 & 67 \\
MRI-ESM2-0 & 5 & 1 & 1 & 1 & 68
\end{tabular}

wind speed, and cloud area fraction are downloaded with a monthly temporal resolution. The regional means are calculated from the original grid resolution, whereas for the maps the simulations are regridded onto a $1^{\circ} \times 1^{\circ}$ grid using a bilinear interpolation approach. We considered all available ensemble members from each model at the time we started this study. The names of models and their ensemble member counts are listed in Table 1

\section{Computation of the SPEI drought index}

The SPEI index ${ }^{18}$ is a multiscalar drought index calculated from monthly precipitation $(P)$ and potential evapotranspiration $\left(E_{0}\right)$. Computation of SPEI index is based on the so-called climatic water balance defined as $D_{i}={ }_{P i}-E_{0 i}$. One advantage of SPEI index is that it can be obtained for different accumulation periods, by aggregating the values of the climatic water balance over different time scales. This allows investigating different types of droughts by adjusting the accumulation period ${ }^{48,49}$. In our study, we use an accumulation period of 6 months (SPEI6) to capture the seasonal development of the drought and a WMO standard period from 1971 to 2000 as the reference period. A 6-month accumulation period is reasonable and widely used in the literature as it filters out short term anomalies, captures seasonal development of drought (e.g., from snow drought in winter to "classical rainfall deficit droughts" in summer) and correlates well with hydrological droughts ${ }^{50}$. The climatic water balance accumulations over 6 months periods are then standardized with a loglogistic distribution. Based on this distribution function, the SPEI values are standardized into a consistent scale and hence can be compared across space regardless of the climatology. Positive and negative SPEI values correspond to relatively wet and dry conditions, respectively whereas a SPEI of near 0 indicates near normal climatology (i.e., $\sim 50^{\text {th }}$ percentile of the cumulative distribution function). For further details, we refer the interested reader to ${ }^{18}$.

We used precipitation $(P)$ directly from the CMIP6 simulations. The monthly $\mathrm{E}_{0}$, however, is computed with the FAO-56 Penman-Monteith equation (using a short reference crop with a height of $0.12 \mathrm{~m}$ ): ${ }^{51}$

$E_{0}=\frac{0.408 \times \Delta \times\left(R_{n}-G\right)+\gamma \frac{900}{T+273} \times U \times\left(e_{a}-e_{d}\right)}{\Delta+\gamma(1+0.34 U)}$

where $\Delta$ is the slope of the saturation vapor pressure function, $\gamma$ is the psychrometric constant, $T$ is the mean air temperature and $U_{2}$ is the average near surface wind. Furthermore, $e_{a}$ and $e_{s}$ are mean saturation 
vapor pressure of the air and saturation vapor pressure at the $\mathrm{kPa}$ which are determined by minimum and maximum temperature. $R_{n}$ and $G$ are the net radiation and the soil heat flux (more details and the corresponding parametrization of $R_{n}-\mathrm{FAO}$ and $G$ are presented in Ref. ${ }^{51}$ ). The $R_{n}$ is estimated by cloud cover, minimum, and maximum temperature, whereas $G$ is determined by the average temperature. The required input datasets include the maximum and minimum temperature, wind speed, and cloud area fraction and a $1^{\circ}$ elevation data from the Rand Corporation/Scripps Institution of Oceanography (accessed through the Cooperative Institute for Climate, Ocean, and Ecosystem Studies http://research.jisao.washington.edu/data_sets/elevation/).

SPEI6 and $E_{0}$ were computed for the mean of the realizations of each model separately using the R package SPEI ${ }^{18,19}$. Furthermore, the SPEI6 and the $E_{0}$ dataset are averaged seasonally (December, January and February (DJF); March, April and May (MAM); June, July and August (JJA); September, October and November (SON)) to obtain a more comprehensive perspective about summer season droughts. Ensemble means of both SPEI6 and $E_{0}$ are then computed for summer (JJA). To study droughts regionally, area averaged estimates are computed for the selected climate regions introduced in the IPCC (AR6) Assessment reports ${ }^{23}$.

\section{Model evaluation}

To evaluate the consistency of the climate model simulations with observations, we perform two different comparisons. We use data from CRU TS v. $4.05^{52}$ to evaluate temperature and precipitation simulations and data from SPElbase v.2.6 $6^{18}$ to assess drought conditions. The former compares the average climate of WMO standard period 1971 to 2000 in summer considering three climate variables. To determine deviations between modelled and observed climate conditions, the ensemble mean from model simulations during 1971-200 was subtracted from the average value of the observations. A positive (negative) value indicates that the ensemble mean of the models has a greater (smaller) value than the observations (overestimation).

We also compare the differences between the means of two time periods: 1975 to $1989\left(\mathrm{t}_{1}\right)$ and 2000 to $2014\left(\mathrm{t}_{2}\right)$ in model simulations (m) and observations (o). By comparing the change in the two periods one can compare change in model simulations relative to the observations $(\mathrm{d}=\mathrm{m}-\mathrm{o})$. A negative value indicates a stronger trend between the two time periods in the observations than the climate model ensemble (a positive value represents the opposite).

\section{Occurrence rate statistics}

The initial data set for the computation of the extreme statistics consists of the SPEI time series for the AR6 regions from all models and their corresponding ensemble means. The advantage of using this drought index is that it is standardized on a given period and a predefined distribution. Therefore, each SPEI value corresponds to a predefined probability. Here, we choose the threshold of -1.5 meaning that all occurrences of SPEl below the threshold would be considered as drought. This threshold generally corresponds to a moderate to extreme drought event. The probability that a value is below this threshold is predefined by the distribution function a 6.7\% (approximately one event in 15 years). This or similar thresholds have been used in previous studies of extreme droughts ${ }^{8,53}$. Then, time series of extreme droughts defined as SPEI value $<-1.5$ are generate for analysis of occurrence probability.

Using the extreme drought time series, one can calculate the occurrence probability. The occurrence can be considered as an indicator of risk over a time interval as follows: ${ }^{54}$

$\hat{\lambda}(T)=h^{-1} \sum_{j=1}^{m} K\left(\frac{\left[T-T_{\text {ext }}(j)\right]}{h}\right)$

The variable $h$ is the bandwidth, $T_{\text {ext }}(j)$ is an extreme year, $m$ is the sample size of extremes and $K$ is the Gaussian kernel. The size of the bandwidth defines how many data points contribute to the occurrence rate estimation. To find the most appropriate bandwidth for the dataset, the cross-validation bandwidth selector based on Ref. ${ }^{55}$ is used. Based on the cross validation analysis a bandwidth of $h=9$ is used in this study which is consistent with the physical knowledge of underlying processes.

Sample size plays an important role in analysis of extremes. In methods that involve a window or bandwidth, some samples from the beginning or end of the record may not be used - an issue know as boundary effect/ bias. Since our time series is temporally limited to the time frame of the SSPs, we aimed to use the entire period and the largest sample possible.
Follwing ${ }^{54}$, an elegant way to deal with the boundary bias problem is the generation of pseudo data outside the observation period, which can be achieved through the reflection of the dataset at boundaries. We used the reflection technique to be able to ensure using the largest possible sample size. We note that we computed the median of the occurrence rate as the average of the occurrence rates of all models.

Furthermore, it is also important to obtain a measure of uncertainty and to determine if it is significant. For this purpose, we computed the $25^{\text {th }}$ and $75^{\text {th }}$ percentile of the occurrence rates for all models. This technique provides more information about the ensemble spread.

It is also possible to use occurrence rate computation for hypothesis testing ${ }^{54}$. In our case, we tested whether the occurrence rate is constant $\left(\mathrm{H}_{0}\right)$ or increasing/decreasing $\left(\mathrm{H}_{1}\right)$ using the following test statistics: ${ }^{56}$

$U_{C L}=\frac{\sum_{j=1}^{m} \frac{T_{\text {ext }}(j)}{m}-[T(n)+T(1)] / 2}{[T(n)-T(1)](12 m)^{1 / 2}}$

where $n$ is the total sample size. Since the distribution of $U_{\mathrm{cl}}$ approaches a standard normal shape with increasing sample size $(m)$, a $p$-value can be calculated to reject or not reject $\mathrm{H}_{0}{ }^{54}$. $U_{C L}$ test statistics allows investigating the alternative hypothesis as changing, increasing or decreasing occurrences using the corresponding $m$.

\section{DATA AVAILABILITY}

All data from CMIP6 simulations (historical, SSP1-2.6, SSP2-4.5 and SSP5-8.5) used in our analyses are freely available from the Earth System Grid Federation (https://esgfdata.dkrz.de/projects/cmip6-dkrz//)

\section{CODE AVAILABILITY}

The postprocessing of the model output data has been done with the Climate Data Operators ${ }^{69}$ and the corresponding Python binding. Furthermore, the computation of the FAO-56 Penman-Monteith $\mathrm{E}_{0}$ and of SPEI have been done with the SPEI package (https://cran.r-project.org/web/packages/SPEI/SPEl.pdf; version 1.7) in $\mathrm{R}$ (version 4.0.2). The used tools and packages are freely available.

Received: 7 April 2021; Accepted: 28 October 2021; Published online: 02 December 2021

\section{REFERENCES}

1. Chiang, F., Mazdiyasni, O. \& AghaKouchak, A. Evidence of anthropogenic impacts on global drought frequency, duration, and intensity. Nat. Commun. 12, 2754 (2021).

2. Humphrey, V. et al. Sensitivity of atmospheric CO 2 growth rate to observed changes in terrestrial water storage. Nature 560, 628-631 (2018).

3. Lu, J., Carbone, G. J. \& Grego, J. M. Uncertainty and hotspots in 21 st century projections of agricultural drought from CMIP5 models. Sci. Rep. 9, 4922 (2019).

4. Vicente-Serrano, S. M., Quiring, S. M., Peña-Gallardo, M., Yuan, S. \& DomínguezCastro, F. A review of environmental droughts: Increased risk under global warming? Earth-Sci. Rev. 201, 102953 (2020).

5. Challinor, A. J., Simelton, E. S., Fraser, E. D. G., Hemming, D. \& Collins, M. Increased crop failure due to climate change: assessing adaptation options using models and socio-economic data for wheat in China. Environ. Res. Lett. 5 034012 (2010)

6. Loarie, S. R. et al. The velocity of climate change. Nature 462, 1052-1055 (2009)

7. Dai, A., Zhao, T. \& Chen, J. Climate change and drought: a precipitation and evaporation perspective. Curr. Clim. Change Rep. 4, 301-312 (2018).

8. Vicente-Serrano, S. M. et al. Global characterization of hydrological and meteorological droughts under future climate change: the importance of timescales, vegetation-CO2 feedbacks and changes to distribution functions. Int. J. Climatol. 40, 2557-2567 (2019).

9. Taylor, K. E., Stouffer, R. J. \& Meehl, G. A. An overview of CMIP5 and the experiment design. Bull. Am. Meteorol. Soc. 93, 485-498 (2012).

10. Seager, R. et al. Climate variability and change of mediterranean-type climates. J. Clim. 32, 2887-2915 (2019).

11. Cook, B. I., Smerdon, J. E., Seager, R. \& Coats, S. Global warming and 21 st century drying. Clim. Dyn. 43, 2607-2627 (2014).

12. Cook, E. R. et al. Old World megadroughts and pluvials during the Common Era. Sci. Adv. 1, e1500561 (2015).

13. Berg, A., Sheffield, J. \& Milly, P. C. D. Divergent surface and total soil moisture projections under global warming. Geophys. Res. Lett. 44, 236-244 (2017). 
14. Lemordant, L., Gentine, P., Swann, A. S., Cook, B. I. \& Scheff, J. Critical impact of vegetation physiology on the continental hydrologic cycle in response to increasing $\mathrm{CO}_{2}$. Proc. Natl Acad. Sci. USA 115, 4093-4098 (2018).

15. Mankin, J. S., Seager, R., Smerdon, J. E., Cook, B. I. \& Williams, A. P. Mid-latitude freshwater availability reduced by projected vegetation responses to climate change. Nat. Geosci. 12, 983-988 (2019).

16. Eyring, V. et al. Overview of the Coupled Model Intercomparison Project Phase 6 (CMIP6) experimental design and organization. Geosci. Model Dev. 9, 1937-1958 (2016).

17. Mishra, A. K. \& Singh, V. P. A review of drought concepts. J. Hydrol. 391, 202-216 (2010).

18. Vicente-Serrano, S. M., Beguería, S. \& López-Moreno, J. I. A multiscalar drought index sensitive to global warming: the standardized precipitation evapotranspiration index. J. Clim. 23, 1696-1718 (2010).

19. Beguería, S., Vicente-Serrano, S. M., Reig, F. \& Latorre, B. Standardized precipitation evapotranspiration index (SPEI) revisited: parameter fitting, evapotranspiration models, tools, datasets and drought monitoring. Int. J. Climatol. 34, 3001-3023 (2014).

20. Markonis, Y. et al. The rise of compound warm-season droughts in Europe. Sci. Adv. 7, eabb9668 (2021)

21. Stagge, J. H., Tallaksen, L. M., Gudmundsson, L., Loon, A. F. V. \& Stahl, K. Candidate distributions for climatological drought indices (SPI and SPEI). Int. J. Climatol. 35, 4027-4040 (2015).

22. O'Neill, B. C. et al. The scenario model intercomparison project (ScenarioMIP) for CMIP6. Geosci. Model Dev. 9, 3461-3482 (2016).

23. Iturbide, M. et al. An update of IPCC climate reference regions for subcontinental analysis of climate model data: definition and aggregated datasets. Earth Syst. Sci. Data 12, 2959-2970 (2020).

24. Yamada, T. J., Seang, C. N. \& Hoshino, T. Influence of the long-term temperature trend on the number of new records for annual maximum daily precipitation in Japan. Atmosphere 11, 371 (2020).

25. Feng, S. et al. Projected climate regime shift under future global warming from multi-model, multi-scenario CMIP5 simulations. Glob. Planet. Change 112, 41-52 (2014).

26. Fan, X., Duan, Q., Shen, C., Wu, Y. \& Xing, C. Global surface air temperatures in CMIP6: historical performance and future changes. Environ. Res. Lett. 15, 104056 (2020).

27. Lee, J.-Y. \& Wang, B. Future change of global monsoon in the CMIP5. Clim. Dyn. 42, 101-119 (2014).

28. Wang, B., Jin, C. \& Liu, J. Understanding future change of global monsoons projected by CMIP6 models. J. Clim. 33, 6471-6489 (2020).

29. Liu, X., Li, C., Zhao, T. \& Han, L. Future changes of global potential evapotranspiration simulated from CMIP5 to CMIP6 models. Atmos. Ocean. Sci. Lett. 13, 568-575 (2020).

30. Orlowsky, B. \& Seneviratne, S. I. Global changes in extreme events: regional and seasonal dimension. Clim. Change 110, 669-696 (2012).

31. Orlowsky, B. \& Seneviratne, S. I. Elusive drought: uncertainty in observed trends and short- and long-term CMIP5 projections. Hydrol. Earth Syst. Sci. 17, 1765-1781 (2013).

32. Mariotti, A., Pan, Y., Zeng, N. \& Alessandri, A. Long-term Climate Change in the Mediterranean region in the midst of decadal variability. Clim. Dyn. 44, 1437-1456 (2015).

33. Cook, B. I. et al. Twenty-first century drought projections in the CMIP6 forcing scenarios. Earths Future 8, e2019EF001461 (2020).

34. IPCC. Climate Change 2013 - The Physical Science Basis: Working Group I Contribution to the Fifth Assessment Report of the Intergovernmental Panel on Climate Change. (Cambridge University Press, 2013). https://doi.org/10.1017/ CBO9781107415324.

35. Zhao, T. \& Dai, A. The magnitude and causes of global drought changes in the twenty-first century under a low-moderate emissions scenario. J. Clim. 28, 4490-4512 (2015).

36. Tian, L., Yuan, S. \& Quiring, S. M. Evaluation of six indices for monitoring agricultural drought in the south-central United States. Agric. Meteorol. 249, 107-119 (2018).

37. Zhao, C. et al. Temperature increase reduces global yields of major crops in four independent estimates. Proc. Natl Acad. Sci. USA 114, 9326-9331 (2017).

38. Grolle, J. Historical case studies of famines and migrations in the West African Sahel and their possible relevance now and in the future. Popul. Environ. 37, 181-206 (2015).

39. Barnosky, A. D. et al. Approaching a state shift in Earth's biosphere. Nature 486, 52-58 (2012).

40. Davis, M. B. \& Shaw, R. G. Range shifts and adaptive responses to quaternary climate change. Science 292, 673-679 (2001).

41. Koven, C. D. Boreal carbon loss due to poleward shift in low-carbon ecosystems. Nat. Geosci. 6, 452-456 (2013).
42. Anderegg, W. R. L., Kane, J. M. \& Anderegg, L. D. L. Consequences of widespread tree mortality triggered by drought and temperature stress. Nat. Clim. Change 3, 30-36 (2013).

43. Cook, B. I., Mankin, J. S. \& Anchukaitis, K. J. Climate change and drought: from past to future. Curr. Clim. Change Rep. 4, 164-179 (2018).

44. Knutti, R. \& Sedláček, J. Robustness and uncertainties in the new CMIP5 climate model projections. Nat. Clim. Change 3, 369-373 (2013).

45. Davini, P. \& D'Andrea, F. From CMIP3 to CMIP6: northern hemisphere atmospheric blocking simulation in present and future climate. J. Clim. 33, 10021-10038 (2020).

46. Trugman, A. T., Medvigy, D., Mankin, J. S. \& Anderegg, W. R. L. Soil moisture stress as a major driver of carbon cycle uncertainty. Geophys. Res. Lett. 45, 6495-6503 (2018).

47. Seneviratne, S. I. \& Hauser, M. Regional climate sensitivity of climate extremes in CMIP6 versus CMIP5 multimodel ensembles. Earths Future 8, e2019EF001474 (2020).

48. Vicente-Serrano, S. M. et al. Performance of drought indices for ecological, agricultural, and hydrological applications. Earth Interact. 16, 1-27 (2012).

49. Hayes, M., Svoboda, M., Wall, N. \& Widhalm, M. The Lincoln declaration on drought indices: universal meteorological drought index recommended. Bull. Am. Meteorol. Soc. 92, 485-488 (2011).

50. López-Moreno, J. I. et al. Hydrological response to climate variability at different time scales: a study in the Ebro basin. J. Hydrol. 477, 175-188 (2013).

51. Allen, R. G., Smith, M., Perrier, A. \& Pereira, L. S. An update for the definition of reference evapotranspiration. ICID Bull. 43, 1-34 (1994).

52. Harris, I., Osborn, T. J., Jones, P. \& Lister, D. Version 4 of the CRU TS monthly highresolution gridded multivariate climate dataset. Sci. Data 7, 109 (2020).

53. Haile, G. G. et al. Projected impacts of climate change on drought patterns over East Africa. Earths Future 8, e2020EF001502 (2020).

54. Mudelsee, M. Statistical analysis of climate extremes. (Cambridge University Press, 2020). https://doi.org/10.1017/9781139519441.

55. Brooks, M. M. \& Marron, J. S. Asymptotic optimality of the least-squares crossvalidation bandwidth for kernel estimates of intensity functions. Stoch. Process. Their Appl. 38, 157-165 (1991).

56. Cox, D. R. \& Lewis, P. A. W. The statistical analysis of series of events. (Springer Netherlands, 1966). https://doi.org/10.1007/978-94-011-7801-3.

57. Dix, M. et al. CSIRO-ARCCSS ACCESS-CM2 model output prepared for CMIP6 CMIP. (2019) https://doi.org/10.22033/ESGF/CMIP6.2281.

58. Ziehn, T. et al. CSIRO ACCESS-ESM1.5 model output prepared for CMIP6 CMIP. (2019) https://doi.org/10.22033/ESGF/CMIP6.2288.

59. Semmler, T. et al. AWI AWI-CM1.1MR model output prepared for CMIP6 CMIP. (2018) https://doi.org/10.22033/ESGF/CMIP6.359.

60. EC-Earth Consortium (EC-Earth). EC-Earth-Consortium EC-Earth3 model output prepared for CMIP6 CMIP. (2019) https://doi.org/10.22033/ESGF/CMIP6.181.

61. EC-Earth Consortium (EC-Earth). EC-Earth-Consortium EC-Earth3-Veg model output prepared for CMIP6 CMIP. (2019) https://doi.org/10.22033/ESGF/CMIP6.642.

62. Volodin, E. et al. INM INM-CM4-8 model output prepared for CMIP6 CMIP. (2019) https://doi.org/10.22033/ESGF/CMIP6.1422.

63. Volodin, E. et al. INM INM-CM5-0 model output prepared for CMIP6 CMIP. (2019) https://doi.org/10.22033/ESGF/CMIP6.1423.

64. Boucher, O., Denvil, S., Caubel, A. \& Foujols, M. A. IPSL IPSL-CM6A-LR model output prepared for CMIP6 CMIP. (2018) https://doi.org/10.22033/ESGF/ CMIP6.1534.

65. Tatebe, H. \& Watanabe, M. MIROC MIROC6 model output prepared for CMIP6 CMIP. (2018) https://doi.org/10.22033/ESGF/CMIP6.881.

66. Jungclaus, J. et al. MPI-M MPIESM1.2-HR model output prepared for CMIP6 CMIP. (2019) https://doi.org/10.22033/ESGF/CMIP6.741.

67. Wieners, K.-H. et al. MPI-M MPIESM1.2-LR model output prepared for CMIP6 CMIP. (2019) https://doi.org/10.22033/ESGF/CMIP6.742.

68. Yukimoto, S. et al. MRI MRI-ESM2.0 model output prepared for CMIP6 CMIP. (2019) https://doi.org/10.22033/ESGF/CMIP6.621.

69. Schulzweida, U. CDO User Guide. (2019) https://doi.org/10.5281/ZENODO.3539275.

\section{ACKNOWLEDGEMENTS}

Funding by the AWI Strategy Fund Project - PalEX (D.F.B.) and by the Helmholtz Climate Initiative - REKLIM (M.I.) is gratefully acknowledged. A.A. is supported by NOAA MAPP. MI and GL are supported by Helmholtz Association through the joint program 'Changing Earth - Sustaining our Future' (PoF IV) program of the AWI.

\section{AUTHOR CONTRIBUTIONS}

All authors contributed to the study and gave final approval for publication. 


\section{FUNDING}

Open Access funding enabled and organized by Projekt DEAL.

\section{COMPETING INTERESTS}

The authors declare no competing interests.

\section{ADDITIONAL INFORMATION}

Supplementary information The online version contains supplementary material available at https://doi.org/10.1038/s41612-021-00218-2.

Correspondence and requests for materials should be addressed to Daniel F. Balting.

Reprints and permission information is available at http://www.nature.com/ reprints
Publisher's note Springer Nature remains neutral with regard to jurisdictional claims in published maps and institutional affiliations.

(i) Open Access This article is licensed under a Creative Commons Attribution 4.0 International License, which permits use, sharing, adaptation, distribution and reproduction in any medium or format, as long as you give appropriate credit to the original author(s) and the source, provide a link to the Creative Commons license, and indicate if changes were made. The images or other third party material in this article are included in the article's Creative Commons license, unless indicated otherwise in a credit line to the material. If material is not included in the article's Creative Commons license and your intended use is not permitted by statutory regulation or exceeds the permitted use, you will need to obtain permission directly from the copyright holder. To view a copy of this license, visit http://creativecommons. org/licenses/by/4.0/.

(c) The Author(s) 2021 